\title{
LegalZoom Co-Founder: Trick Yourself to do the Impossible
}

\section{Nicholas Vitalari (Elasticity Labs)}

\section{KEYWORDS: Entrepreneurship, Innovation,} Leadership, Legal, Learn From Leaders.

Is it possible to transform a staid and professionally respectable but entrenched legal industry? Yes, particularly when one of your startup founders is a multitalented serial entrepreneur, computer scientist and lawyer. Meet Eddie Hartman, who is Chief Product Officer and a co-founder of LegalZoom, the successful startup that has become a \$200+ million transformational powerhouse in the legal services industry. In this interview, Eddie talks about the critical mindset necessary for entrepreneurial success -including tricking yourself into doing the impossible -the importance of failure, the impact of mentors, and the personal experiences that helped him become a serial entrepreneur, inventor and industry transformer. 